\title{
Article \\ Soil arthropods indicate the range of plant-facilitation on the soil of Mediterranean drylands
}

\author{
Fernando Meloni ${ }^{1,2,+*(\mathbb{D})}$, Alexandre Souto Martinez ${ }^{1,2,+}(\mathbb{D}$ \\ 1 Department of Physics, FFCLRP, University of São Paulo, Av Bandeirantes - 3900, Ribeirão Preto, Brazil \\ 2 Instituto Nacional de Ciência e Tecnologia de Sistemas Complexos (INCT-SC), Dr. Xavier Sigaud - 150, Rio \\ de Janeiro, Brazil \\ * Correspondence: melonifernando@yahoo.com.br; fernandomeloni@usp.br; \\ + These authors contributed equally to this work.
}

\begin{abstract}
Drylands are arid and semiarid ecosystems, where the lack of rains imposes harsh conditions for the survival of organisms. These ecosystems are also susceptible to degradation and desertification, and their conservation depends on the understanding of the ecological functioning of vegetation and soil. In drylands, the vegetation is spatially structured as a mosaic of patches (vegetation) and interpatches (bare soil), a consequence of plant-plant interactions (facilitation and competition). Empirical data and modeling approaches reinforce the role of ecological facilitation for the maintenance of all organisms in drylands. However, the actual range of facilitation is still poorly known. Here, we explored data of meso- and micro-arthropods found in soil as bioindicators to infer the range of facilitation provided by plants to soil. We regarded data of abundances and species densities (independent samples) collected in random patches and bare soil places as dependent variables. Data of patch size and distances between bare soil and patches were arranged in a single shuffle, producing a 1-d coordinate system centered at the border of the patch. Discrete portions of this system are taken to calculate averages and variances of abundance and species density, and we investigated how soil communities variate across the patch border. We employ techniques of signal analysis to reduce the data noise and obtain a smooth and continuous behavior, which allowed us to fit a logistic function. Our findings indicate that soil communities suddenly change from simple patterns to numerous and diverse communities in bare soil regions, meaning that the influence of vegetation on soil goes beyond the patch border. We interpreted the variations in fauna as a consequence of the positive influence provided by plants (or its lack) on surrounding bare soil. We observe a fast decaying of fauna quantities at $0.35 \mathrm{~m}$ outside the patch border, a threshold that reveals the mean range of facilitation provided by plants. However, the changes in soil communities outside the patches seem not necessarily related to the efficiency of soil processes mediated by arthropods, which seem to be more active inside large patches. Concluding, we found a minimum patch-size (radius $\approx 0.5 \mathrm{~m}$ ) able to maintain high diverse communities in soil, and an average distance of vegetation influence along the patch border (halo between 0.35 and $0.50 \mathrm{~m}$ ). This information can be interpreted in terms of facilitation provided by plants to soil conditions, which seems to differ from the quantitative functionality of soil processes. Our findings contribute to the general understanding of the ecological functioning of drylands, as well as to better plan conservation actions.
\end{abstract}

Keywords: ground arthropods; spatial ecology; drylands; logistic function; biological diversity; ecological functioning; threshold values; desertification; conservation.

\section{Introduction}

Arid and semiarid ecosystems cover approximately $40 \%$ of the planet, and are characterized by the low precipitation $(\approx 300 \mathrm{~mm} /$ year $)$, long dry periods, high luminosity, and relatively warm temperatures[1]. These natural features bring consequences for the ecological regime, such as poor soil moisture, low rates of nutrient cycling, and low primary production, which finally culminates in low 
resilence[2,3]. Drylands are also subject to intense human pressure, as billion of people live in these regions, exploring the land for agriculture, livestock, mining, and livelihood resources[4]. The overall consequence is a large susceptibility of these ecosystems to the degradation and environmental changes. Some estimations point out that from 10 to $20 \%$ of worldwide drylands are under desertification[4,5]. This scenario produces an urgent demand for studies aimed on disentangling the ecological functioning of drylands and to revert the degradation, topics that remain not entirely understood.

The severe environmental conditions impose ecological constrains to the living organisms of drylands. Their survival are mainly conditioned to (a) their physiological adaptations, and also (b) to the ecological interactions with further organisms [6-10]. Although (a) and (b) are not completely independent components, our focus relies on the role of ecological interactions. The Stress Gradient Hypothesis (SGH) predicts that some biological interactions like ecological facilitation are essential for the maintenance of biological communities in harsh environments[11,12]. Facilitation relies on positive non-trophic interactions between different organisms, where the ecological activity of one brings benefits for the fitness of another[13]. Although the mechanisms and drivers may greatly vary, the most common for harsh environments embrace resources availability, niches, shelters, and amelioration of abiotic conditions[14-17]. The current knowledge about drylands attributes great importance to facilitation as driver of vegetation spatial patterns, which is often discussed in terms of the general functioning and collapse of these systems[3,18].

In drylands, the vegetation is not continuous. Instead it is often arranged in a mosaic structure (patches, for short), where plants occur as well-defined vegetation patches surrounded by bare soil regions, named as interpatches[19]. The spatial organization in patches and interpatches arises from the interplay between plant-plant facilitation and competition in the context of water limitation of drylands[18,20]. For plants, one of the most usual indicators of facilitation in harsh environments concerns the spatial aggregation of individuals[21,22], which has been employed to evaluate facilitation in worldwide drylands[23]. This indicator relies on the proper concept of facilitation: the presence of an organism, named facilitator, which is adapted to more stressful conditions, attenuate the local conditions and enable that organisms, named facilitated, grow in rates significantly higher than they would do in the absence of the facilitator[15]. This process results in a biased spatial distribution of organisms and also species, which can be assessed and measured. To address this topic is important because it may improve the understanding of the ecological dynamics of dryalnds, which is essential for formulating efficient strategies of conservation and restoration[15,24,25].

Accordingly, specific consorts between pioneer and secondary species may be regarded in proper timing and spacing sequence, which can foster the ecological dynamics necessary to restore these places. Bearing this in mind, one expects that the fine grain understanding about facilitation may improve our comprehension about "how organisms mutually contribute to the functioning of ecological processes in dryland"[24]. This rationale goes beyond the plant-plant interactions, because plants also affect further organisms living in these places[12,16].

Although the current knowledge testifies the role of plants as a broad facilitator, an important question arises: How far can facilitation effects reach? Indeed, one expects that facilitation results in an umbrella radius, which shall define the chances of seedlings and further organisms to survive[16, $20,26]$. While answering this question is not a trivial task, a first guess can be revealed by the influence of plants on the upper layer of soil[27]. The presence of plants can locally improve the water absorption and organic content in soil layers[16,20,28,29], meaning that the soil moisture could be used to reveal the facilitation range. However, the assessment of long term effects of plant facilitation by direct measures of soil moisture can produce contrasting results[17]. In fact, drylands show scarce rains and high evaporation rates, meaning that soil moisture of the upper layers tend to persist only for short periods[27]. Aware of this fact, some light could be shed on the problem using alternative indicators, like the soil organisms. Soil organisms like arthropods can form high diverse communities and survive for long periods of dryness, and yet are still sensitive to permanent changes in the environment[30-32]. Particularly, the ecological patterns of meso- and microarthropods of 
soil provide great contribution to the understanding of more general processes of soil, such as water and air infiltration, sediments revolving, microorganisms dispersion, facilitation, among others[33]. Many of these processes contribute directly or indirectly with nutrient cycling and contribute for the maintenance of biological communities. For these reasons, soil arthropods are considered good indicators of soil health[34-36].

In turn, we conjecture that soil arthropods could also provide rich information about the spatial range of plant facilitation. This hypothesis finds support in previous findings, which suggests that soil arthropods are much more affected by the amount of vegetation than by the plant diversity in worldwide ecosystems, a pattern that is even more remarkable for harsh environments [7]. Independent studies carried out in drylands[37-41] confirm the correlation between ground arthropods and vegetation spatial pattern also for the local scale. Soil layers under patches bear communities with large abundance and species density, while bare soil regions show lesser organisms also belonging to fewer taxa. Differences between soil communities living patches and interpatches suggest that patch border defines an important constraint for the activity of soil arthropods in drylands[39,41]. However, the amelioration provided by plants tends to go beyond patch borders, reaching the bare soil regions[17]. Indeed, patch sizes and the distance between patches also exert quantitative effect on soil fauna, a relationship that is better appreciated when showing abundances and species densities in the logarithmic scale[41]. The strong and contrasting influence of patches and interpatches on soil organisms often decay close to the patch border, which provides insights for an alternative approach. For instance, instead of considering soil arthropods found in patches and interpatches as independent compartments, we hypothesize to be possible to analyze both as different parts of the same compartment. In these terms, patches and interpatches are opposite sides of a continuous spatial system, which is subject to a switching close to the patch border. If this hypothesis is consistent, one would be possible to propose a unique mathematical description to predict quantitative variations of soil arthropods across the patch border. Most importantly, these variations could be used to infer the range of plant influence on soil groups. Summarizing, this achievement would allow us to analyze and interpret data of soil arthropods as the result of a well-behaved function, and thus, the faunal patterns could finally reveal the range of influence of plants on soil organisms. However, this hypothesis is still untested.

Here, we demonstrate that the spatial distribution of soil fauna in drylands is continuous along the patch border. For this, we assess how the patch-size (radius) and distance from patch-borders are associated with communities of ground arthropods in patches and inter-patches. The quantitative information of fauna is linked to the range of influence produced by vegetation on the surrounding bare soil, which is a halo of influence produced by plants of about $0.50 \mathrm{~m}$ around patches. To obtain this result, we evaluated data of arthropods, abundance and species densities, and data of vegetation. Logistic functions are used to fit the faunistic quantities. The facilitation range is obtained from derivative values from the fitted curves. We discuss the implications of our findings in ecological terms, indicating how the patterns of ground arthropods reveal the facilitation and the functional activity in drylands, linking how the logarithmic and observable scales provide information from different ecological aspects. This information is paramount for planning restoration projects in semiarid regions, and it can improve our understanding of the relationship between vegetation spatial patterns and the range of facilitation provided by plants.

\section{Materials and Methods}

This study investigates data of soil fauna and vegetation spatial patterns collected in Cabezo de la Plata, Murcia, Spain. The region is characterized as semiarid, with precipitation $\approx 300 \mathrm{~mm} /$ year, subject to long dry periods. The soils are haplic calcisols and lithic leptosols[42], influenced by long term land use [43]. The statistical distribution of patch sizes found in this region [44] stresses the role of vegetation cover to predict desertification [45], the effect of grazing and dryness on plant-plant 
interactions [46,47], the influence of patch sizes and distance between patches on the abundance and richness of soil fauna[41].

All samples were obtained in short time interval, between June and August, to avoid important seasonal variations. The data set embraces samples obtained in patches (79) and in interpatches (70). The data are almost all formed by registers explored in the Ref.[41], with some additional entries ${ }^{1,2}$. The samples were collected in 14 independent semiarid plots with wide spectra of vegetation covers. For each plot, 5 patches were randomly selected to be measured and to obtain a soil sample; while 5 soil samples were obtained from interpatch regions located beside the sampled patches (Fig. 1A). For each interpatch sample, we delimited a four-side polygon formed by the four-nearest neighbor patches, which were the vertices of this polygon. The interpatch sample was taken at the middle coordinate (centroid; Fig. 1A). Each soil sample taken in patch and interpatch is equivalent and represents 1L of top soil layer (until $10 \mathrm{~cm}$ deep), plus the litter layer immediately above (if present)[32,48]. In laboratory, the meso and microarthropods of soil were extracted using modified Berlese-Tullgren funnels, counted and identified.

Each soil sample $k$ comprises data of ground arthropods, abundance $A_{k}$ and species density $\rho_{K}$; and two descriptors of vegetation spatial patterns, the patch radius $R_{k}$ (meters), which refers to the size of the patch immediately above the sample; and $\bar{D}_{k}$ (meters), as the average distance to the four-nearest points showing any vegetation. The values of $A$ and $\rho$ are obtained by counting individuals and species of each soil sample (densities). According to the definitions of $R$ and $\bar{D}$, a sample $m$ obtained in the soil under a patch shows $R_{m} \neq 0$ and $\bar{D}_{m}=0$ (no distance from vegetation); while a sample $n$ obtained in the bare soil $P_{n}=0$ (no patches immediately above) and $\bar{D}_{n} \neq 0$ (Fig.1A). Hence, the patch size is assumed as the most important influence for $A$ and $\rho$ observed in patch samples ${ }^{3}$, while the distance the distance between the local of bare soil and the neighbor patches is assumed as the most important descriptor of $A$ and $\rho$ found in the soil of interpatches.

1 The new data entries were necessary because the registers explored in Ref. [41] contained only few samples of large patches (radius $R>1.0 \mathrm{~m}$ ), which could limit our analyses. Hence, the data set was complemented with 10 additional samples, all of them representing large patches from the same region.

2 We notice that in the studied region, patches are predominantly constituted by the species Stipa tenacissima L. A., sometimes associated with some additional common species in small proportion. Additionally to the size, the new entries were obtained in patches also bearing a small individual of Pinus sp among the ordinary species composition, a factor that is not explicitly addressed by our analyses. Although we have no detailed information about the plant composition of each patch, a recent study shows that plant diversity poorly affects the diversity of soil arthropods in harsh environments like drylands[7] and that the vegetation cover is the most important influence under such circumstances.

3 The distribution of $A$ and $\rho$ inside patches are assumed to be uniform. 


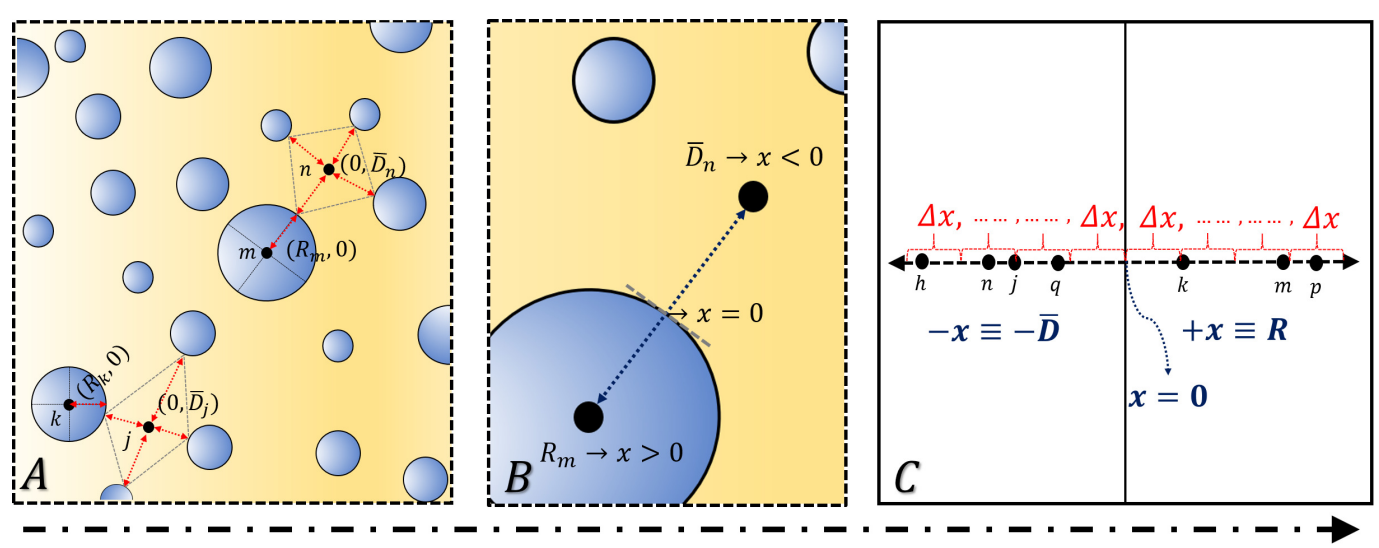

Figure 1. Schematic representations of sampling and the spatial transposition used by the present study. Fig.A depicts a general configuration of patches in dryland landscapes. Soil samples (filled black circles) were acquired in patches (green circles) and in interpatches (yellow matrix), from which arthropods abundance and species densities are measured. The radius of the patch $k$ is $R_{k} i$ and $\bar{D}_{k}$ is the average distance between the interpatch soil sample to 4-nearest patches. Fig.B shows how the line from interpatch middle point runs to the center of a patch, with the patch border being the origin of the coordinate system. In this way, the distance outside from a patch is negative, and positive otherwise. Fig.C depicts the 1-d transposition of all samples in terms of a unified and continuous behavior as a function of $x$. Therefore, soil samples come from different patches and interpatches to form the logistic function that we study. For the analysis, samples are taken into non-overlapping regular intervals of $\Delta x=0.10 \mathrm{~m}$.

\section{Data organization}

Our main hypothesis is that the vegetation patches exert positive influence on the establishment of soil organisms into bare soil regions. This influence can be interpreted as the facilitation effect generated by plants, which broadly affects organisms in drylands[2,16]. The meso and microarthropods of soil are very sensitive to the environmental filters, and they are also benefited by the resources and shelters provided by plants[7,37,41]. Thus, we conjecture that the ground arthropod community could reflect the plant facilitation, which could be revealed by the spatial variation of its abundance and number of species. If so, measures of fauna could inform about the range of plant facilitation in soil. We assess how the patterns of soil fauna found around the border respond to patch sizes and the distance between patches. We expect to use the collective variation of $A$ and $\rho$ values to reveal how far facilitation can reach in bare soil.

To test this hypothesis, we explicitly addressed the spatial coordinates joining $R$ (meters) and $\bar{D}$ (meters) into one single variable $x$. The $x$ values are the subtraction of $R$ and $\bar{D}$ of each sample, obtained as

$$
x_{j}=R_{j}-\bar{D}_{j}
$$

where $j$ is a random sample taken in patch or interpatch. Note that samples of patches show $\bar{D}_{j}=0$, while samples of interpatches show $R_{j}=0$, so that Eq.1 produces $x<0$ if the $\mathrm{i}$-th sample represents an interpatch, and $x>0$ if it represents a patch (Fig.1B). Accordingly, $x$ stores all values of $R$ and $\bar{D}$ in only one axis using same unit (meters), while the signal preserve information about origin (patch: $+x$; interpatch: $-x)$. Therefore, $x$ is a $1-\mathrm{d}$ spatial representation deduced from different sources $(R$ and $\bar{D})$ that allows to consider all samples (that were randomly acquired) to be represented in the same 1-d chute (Fig.1C). This approach enables to plot all values of $A$ and $\rho$ against $x$, in a continuous representation that crosses the patch border and allow to explicitly interpret the multivariate influences of $R$ and $\bar{D}$ on the soil arthropods (Fig.1C). As indicated in the Ref.[49], the advantage of the continuous representation against the binary description of drylands relies on the possibility of employing mathematical analyses to reveal and predict patterns and behaviors. 
Samples of soil fauna ordinarily present large data noise[50]. We formulate a data pretreatment based on signal-analysis techniques for smothing the curves. The first step removed all registers showing zeros and missing data (12 samples). Next, we employed five independent rounds of moving averages, respectively for 3, 4, 5, 6, and 7 points. Each round generated further data points based on the calculated averages that were joined to the original registers. This data pretreatment increased the number of useful registers from 149 to 794 (original + calculated). Overall, it greatly improved the signal-noise ratio and the data set shows a large cloud of points centered on the mean behavior for both, $A$ and $\rho$ along $x$ (Appendix A1). However, it also brought side-effects. The process introduced pseudoreplication to the analysis and it prevented us to calculate real statistical intervals of confidence, forcing us to adopt an alternative approach to infer it (see subsection Analyses).

Previous findings[41] suggest that the influence of vegetation on soil fauna could be better assessed by taking faunal data in the logarithmic scale. Then, we introduce the transformed quantities $N=\ln (A)$ for abundances, and $S=\ln (\rho)$ for species densities. Considering the 794 data points, the following step consisted in to discretize $x$ at regular small intervals of $\Delta x=0.10 \mathrm{~m}$ (Fig.1C). In turn, each discrete interval $k$ delimited by $x+\Delta x$ shows $v$ samples, and the respective values of $N$ and $S$ are used to calculate the averages $\bar{\mu}_{N}^{(k)}$ and $\bar{\mu}_{S}^{(k)}$ as

$$
\bar{\mu}_{N}^{(k)}=\sum_{q=1}^{v} N_{q} / v \quad \text { and } \quad \bar{\mu}_{S}^{(k)}=\sum_{q=1}^{v} S_{q} / v
$$

and variances $\bar{\sigma}_{N}^{2(k)}$ and $\bar{\sigma}_{S}^{2(k)}$ as

$$
\bar{\sigma}_{N}^{2(k)}=\sum_{q=1}^{v}\left(N_{q}-\bar{\mu}_{N}^{2(k)}\right) / v \quad \text { and } \quad \bar{\sigma}_{S}^{2(k)}=\sum_{q=1}^{v}\left(S_{q}-\bar{\mu}_{S}^{2(k)}\right) / v ;
$$

where $q$ is a given sample taken into the $k$-th interval of $x$. Average values and variances are finally used to assess how the arthropod communities variate throughout $x$.

\section{Analyses}

We are particularly concerned about how the soil community varies along the spatial coordinates represented by $x$. Previous findings indicate that abundances and species densities found in patches and interpatches are very different $[37,41]$, which suggest that variations across the patch border tend to abruptly vary. In turn, we search for a possible transition of the community patterns, $A$ and $S$, plotting $\bar{\sigma}_{N}^{2}$ and $\bar{\sigma}_{S}^{2}$ against $x$. We searched for a well-defined peak formed by the variance values. A peak of variance may reveal an interval of $x$ bearing high level of uncertainty about soil communities (values greatly vary in comparison with further ranges of $x$ ). This is the remarkable sign that both patch and interpatch are influencing the interval[45,51,52], and may infer where the patterns of soil community switching from a community of few individuals and species to a more structured community. Therefore, we interpret this interval as an indicator of the region where the effects produced by facilitation on the soil arthropods suddenly decay.

Next, we plotted the average values of $\bar{\mu}_{N}$ and $\bar{\mu}_{S}$ against $x$ with two main objectives. The first one is to confirm or deny the possibility of abrupt changes in the considered quantity, indicated by its variances. The second aim is to construct a predictive curve using a known function and revealing specific threshold mean values. For this, we assumed the behavior of $\bar{\mu}_{N}$ and $\bar{\mu}_{S}$ along $x$ varying as a logistic function[53]. Although the logistic function is just a first approximation to describe the problem, this function can provide great intuition about the average behavior of arthropod quantities along $x$, as detailed below.

The logistic function is expressed as

$$
Y(x)=\frac{Y_{\max }}{1+b e^{-c(x)}}+Y_{\min }
$$


where $Y(x)$ represents one of the faunistic variables $\left(\bar{\mu}_{N}\right.$ or $\left.\bar{\mu}_{S}\right), Y_{\max }$ and $Y_{\min }$ are respectively the maximum and minimum values achieved by $Y ; b$ and $c$ are the growth parameters that mold the $S$-shape. This function is usually employed to fit population growth, which regards time as the independent variable, but we interpret its parameters in terms of the spatial variable. One expects that $Y \rightarrow Y_{\min }$ for samples taken in interpatches coordinates located very far from the patch border $(x \ll 0)$, while $Y \rightarrow Y_{\max }$ for samples obtained in very large patches $(x \gg 0)$.

The variation of $Y$ along $x$ is not homogeneous for the logistic function that shows three regions of interest. The first-order derivative $Y^{\prime}(x)$ is useful to reveal the main $x$ region of interest, the inflection point $x^{*}$, but it cannot clearly indicate the others. Hence, we employ the second-order derivative $Y^{\prime \prime}(x)$, which is able to reveal all regions of interest. The inflection point $x^{*}$ takes place at the $x$-coordinate where $Y^{\prime \prime}(x)$ changes its signal (from + to - ). The $x^{*}$ marks the place where $Y(x)=\frac{Y_{\max }-Y_{\min }}{2}$, revealing where the soil arthropod community suddenly change their quantities, and, consequently, the range of facilitation provided by plants. According to the region where $x^{*}$ takes place, the following interpretation can be done:

- $x^{*}=0$ : the quantities of soil arthropods decay at the patch border. It indicates that facilitation is constrained to regions close to the patch border, which we name as edge facilitation;

- $x^{*}<0$ : the quantities of soil arthropods decay in bare soil regions. The case infers that patch influence (facilitation) persists beyond the patch border. We name it as long range facilitation.

- $x^{*}>0$ : the quantities of soil arthropods decay even inside patches. In that case, the positive influence occurs only for regions covered by the plants, and that interpatch regions negatively affect the conditions inside patches. We name as constrained facilitation.

Furthermore, two other regions of interest, $x_{a}^{*}$ and $x_{b}^{*}$, are also expected for the $Y^{\prime \prime}(x)$. Interpreting the logistic function, the $x_{a}^{*}$ indicates the $x$ coordinates where $Y$ values start to differ from $Y_{\text {min }}$, while $x_{b}^{*}$ where $Y$ values become close to $Y_{\max }$. These are also reference values to interpret the influence of vegetation patterns on soil arthropods. Considering the $\bar{\mu}_{N}$ and $\bar{\mu}_{S}$ values, the respective $x_{a}^{*}$ is interpreted as the maximum range of the facilitation, and $x_{b}^{*}$ as the effective patch radius, that is the minimum patch size that is able to support a dense and diverse community (Fig.1C).

The parameters were set by coupling a recurrent human supervised process, which coupled initial guess and optimization by Generalized Reduced Gradient, and used the maximum likelihood between observed and fitted data as criterion. Concerning the average behaviors described by $f(x)$ and $g(x)$, we fitted the logistic curves $f_{1}(x), f_{2}(x), f_{3}(x), g_{1}(x), g_{2}(x)$, and $g_{3}(x)$, where the indexes respectively represent: 1 - curves fitted for the minimum values; 2 - curves fitted for the average behaviors; and 3 - represent curves for maximum values. The curves of indexes 1 and 3 are interpreted as "intervals of confidence", although they do not truly match such formalism ${ }^{4}$. For clarity, we shall refer the respective second-order derivatives as $f_{1 \rightarrow 3}^{\prime \prime}(x)$ and $g_{1 \rightarrow 3}^{\prime \prime}(x)$.

Last, we plot $f(x)$ and $g(x)$ in the observable scale $\left(A=e^{N}\right.$ and $\left.\rho=e^{S}\right)$ to elucidate the role of the patch sizes and the carrying capacity on the effective shift produced by the scale conversion. Concerning the nature of $N$ and $S$, the analysis addressing $A$ and $\rho$ consider the Eq. 4 as a reference to obtain

$$
\Phi(x)=\exp [Y(x)]=\exp \left(\frac{Y_{\max }}{1+b e^{-c(x)}}+Y_{\min }\right),
$$

where $\Phi(x)$ represents $\bar{\mu}_{A, x}=\exp \left(\bar{\mu}_{N, x}\right)=\exp [f(x)]$ or $\bar{\mu}_{\rho, x}=\exp \left(\bar{\mu}_{S, x}\right)=\exp [g(x)]$. The inflection point obtained for $\Phi^{\prime \prime}(x)$ is given as $x^{(o)}$ to differ from $x^{*}$. This threshold is important to complement our analyses and interpretations, mainly to show how the increase of the carrying capacity indicated by $N_{\max }$ and $S_{\max }$ can affect the $x^{(o)}$ values. By observing the behaviors of $x^{*}$ and $x^{(o)}$, we provide different ecological interpretations for the ecological variables obtained from soil communities.

nucleus of patches.

4 The employment of moving average impedes to obtain true confidence intervals from the statistics. 


\section{Results}

\subsection{Maximum uncertainty}

Concerning the discretization of $x$ by $\Delta x=0.10 \mathrm{~m}$, the analyses of $\bar{\sigma}_{N}^{2}(x)$ and $\bar{\sigma}_{S}^{2}(x)$ along the $x$ coordinates reveal a characteristic region of high uncertainty ranging $-0.75 \mathrm{~m}<x<-0.35 \mathrm{~m}$ (Fig.2A-B). This interval is marked by $N$ and $S$ values showing large deviation among samples, meaning that samples with large and small values of $N$ and $S$ coexist in an interpatch region. Furthermore, the variances abruptly increase at the center of the interval, forming a characteristic peak. For abundances, the behavior is better described by the normalization $\bar{\sigma}_{N}^{2}(x) / \bar{\mu}_{N}(x)$, and the peak takes place in the neighborhood of $x \rightarrow-0.60 \mathrm{~m}$. For species density the normalization $\bar{\sigma}_{S}^{2}(x) / \bar{\sigma}_{\text {Smax }}^{2}$ reveals that the peak takes place around $x \rightarrow-0.55 \mathrm{~m}$ (Fig.2A-B). Accordingly, soil communities shift from simple communities bearing few individuals belonging to few species, to more structured patterns, with a larger number of individuals and species of arthropods. These pieces of evidence indicate that the organization of soil communities markedly changes, and the negative values of $x$ where the peaks exist reveal that such changes occur outside of patches. This is an important indicator of the range of influence exerted by patches on the surrounding regions of bare soil. Additional tests with alternative values of $\Delta x$ confirm the patterns observed for $\Delta x=0.10 \mathrm{~m}$, meaning that results depicted in Fig.A-B are resilient to the grain size used for discretization.

The logistic functions $f_{2}(x)$ and $g_{2}(x)$ respectively adjusted for $\bar{\mu}_{N}$ and $\bar{\mu}_{S}$ were able to properly represent the general behavior of soil communities along $x$ (Fig.2C-D). Both cases indicated that the curves reach an inflection point for $x^{*} \approx-0.35 \mathrm{~m}$ (Fig.2C-D). The threshold $x^{*}$ is coherent with the coordinate where $\bar{\mu}_{N}$ and $\bar{\mu}_{S}$ respectively reach half of $\bar{\mu}_{N \max }$ and $\bar{\mu}_{S \max }$. The second-order derivative of $f_{2}(x)$ and $g_{2}(x)$ confirm the $x^{*}$ thresholds by the signal changes of the curves $f_{2}^{\prime \prime}(x)$ and $g_{2}^{\prime \prime}(x)$ (Fig.2E-F). Furthermore, these curves also reveal two additional thresholds, $x_{a}^{*}$ and $x_{b}^{*}$, which are indicated by two different behavior change along $x$. The $f_{2}^{\prime \prime}(x)$ indicates a region of interest at $x_{a}^{*} \approx-1.15 \mathrm{~m}$, while $g_{2}^{\prime \prime}(x)$ show the same at $x_{a}^{*} \approx-1.25 \mathrm{~m}$. Such values reveal where $\bar{\mu}_{N}$ and $\bar{\mu}_{S}$ assume values that are consistently different from general values found in interpatch samples, which show $\bar{\mu}_{N}>\bar{\mu}_{N \text { min }}$ and $\bar{\mu}_{S}>\bar{\mu}_{S \sin }$. Therefore, they provide an inference about the maximum range of facilitation produced by patches. The region of interest $x_{b}^{*}$ infers where soil communities assume abundances and species richness close those observed into large patches $\left(\bar{\mu}_{N} \approx \bar{\mu}_{N \max }\right.$ and $\bar{\mu}_{S} \approx \bar{\mu}_{S \max }$ ). The $f_{2}^{\prime \prime}(x)$ indcates $x_{b}^{*} \approx 0.55 \mathrm{~m}$, and $g_{2}^{\prime \prime}(x)$ indicates $x_{b}^{*} \approx 0.45 \mathrm{~m}$. They suggest the minimum patch size (radius) necessary for soil arthropod communities reach the maximum local abundance and diversity found in the studied region.

As predicted by variances (Fig.2A-B), functions fitted for extreme cases of $N, f_{1}(x)$ and $f_{3}(x)$, and for $S, g_{1}(x)$ and $g_{3}(x)$, indicated that the inflection points may greatly vary throughout the $x$-coordinates. For $\bar{\mu}_{N_{\max }}$, the variation range from $x \approx-0.90 \mathrm{~m}$ (out of patch) to $x \approx 0.20 \mathrm{~m}$, and for $\bar{\mu}_{S_{\max }}$ from $x=-0.90 \mathrm{~m}$ (out of patch) to $x \approx 0.30 \mathrm{~m}$ (inside patch). Similar variations are observed for the further regions of interest, extending the limit of the positive influence of patches on the interpatches to $x_{a}^{*}=-1.75 \mathrm{~m}(D \leq 1.75 \mathrm{~m})$, and the minimum patch size able to support abundant communities to $x_{b}^{*}=0.75 \mathrm{~m}(R \leq 0.75 \mathrm{~m})$, and diverse communities $x_{b}^{*}=0.95 \mathrm{~m}(R \leq 0.95 \mathrm{~m})$. 

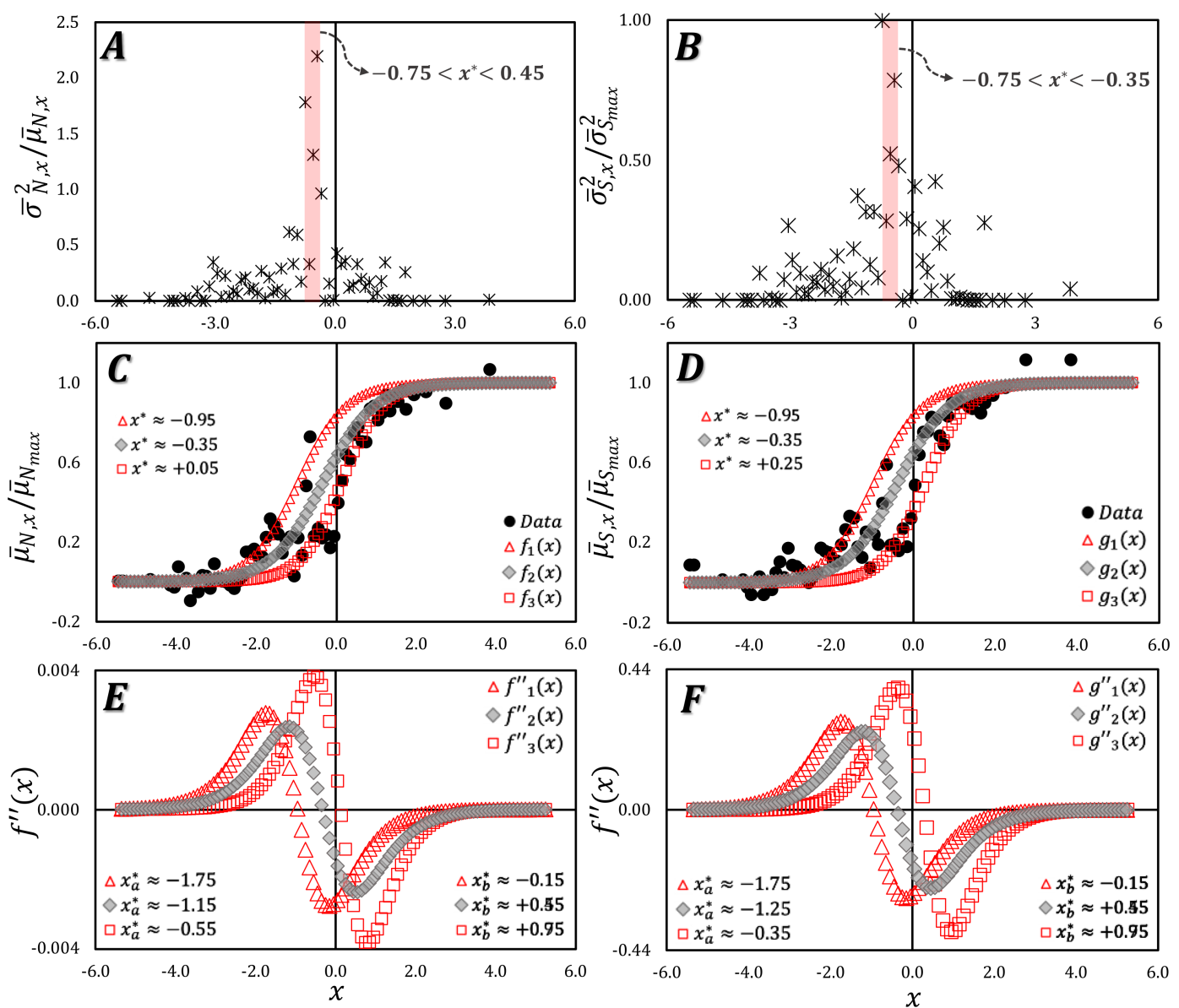

Figure 2. Analysis of THE soil arthropods quantities $N=\ln (A)$ and $S=\ln (R)$ through a 1-d spatial representation $X$ that crosses the patch border. Values of $N$ and $S$ are taking into intervals of $\Delta x=0.10$ $\mathrm{m}$, resuting in their averages and variances $\left(\bar{\mu}_{N} ; \bar{\mu}_{S} ; \bar{\sigma}_{N}^{2} ; \bar{\sigma}_{S}^{2}\right)$. The value $x=0$ represents the patch border; $x>0$ patch size (radius); $x<0$ distances between the patch border and interpatch samples. From outwards to inwards the $\bar{\mu}$ and $\bar{\sigma}^{2}$ plots along $x>0$ represent samples obtained in patches, and for $x<0$, samples were collected in bare soil (interpatches). Figs. $A$ and $B$ depict the peak of variance observed for $\bar{\sigma}_{N}^{2}$ around $x=-0.60 \mathrm{~m}$, and $b a r \sigma_{S}$ around $x=-0.55 \mathrm{~m}$. The peaks and their neighborhood indicate where maximum rate of uncertainty takes place, and samples of large and small abundances and richness coexist. In Figs. $C$ and $D, f_{2}(x)$ and $g_{2}(x)$ respectively indicate the logistic curves that better describe the behavior of $\bar{\mu}_{N}$ and $\bar{\mu}_{S}$ through the $x$ values. Both functions indicate inflection points (change of growth rate) in $x^{*} \approx-0.35 \mathrm{~m}$. These inflections reveal the average distance from the patch border where soil communities reach half of $\bar{\mu}_{N \max }$ and $\bar{\mu}_{S \max }$ values. In Figs. $E$ and $F$, the second order derivatives $f_{2}^{\prime \prime}(x)$ and $g_{2}^{\prime \prime}(x)$ confirm the patterns observed in Figs. $C$ and $D$ (signal change) at $x^{*}$, and point out two further inflection points. The threshold $x_{a}^{*} \approx-1.15 \mathrm{~m}$ indicates the distance from patch border where soil communities starts to show consistent increasing of $\bar{\mu}_{N}$ and $\bar{\mu}_{S}$. It also suggests the maximum range of positive influence of patches on interpatches (facilitation). The $x_{b}^{*} \approx 0.50 \mathrm{~m}$ suggests the average patch size (radius $\approx 0.50 \mathrm{~m}$ ) able to support soil communities with large values of $\bar{\mu}_{N}$ and $\bar{\mu}_{S}$. The curves $f_{1}(x), f_{3}(x), g_{1}(x)$ and $g_{3}(x)$ depicted in Figs. $C, D, E$ and $F$ indicate logistic curves fitted for extreme cases. They provide a reference of error associated with the average behavior described by $f_{2}(x)$ and $g_{2}(x)$.

Despite variations indicated by the limit cases, the Fig.3A-D confirms that the averages curves $f_{2}(x)$ and $\left.g_{(} x\right)$ remain coherent to data even for the observable scale $\left(\bar{\mu}_{A}\right.$ and $\left.\bar{\mu}_{\rho}\right)$. As predicted by the change of scale, the smaller values $\bar{\mu}_{A}$ and $\bar{\mu}_{\rho}$ found in samples of interpatches produced better fit for $x<0$, while $\bar{\mu}_{N}$ and $\bar{\mu}_{S}$ produced better fit for samples taken in patches. Values of $x^{*}$ obtained for $f_{2}(x)$ and $g_{2}(x)$ are immutable to variations in $N_{\max }$ and $S_{\max }$, which is indeed predicted for the logistic 
function. However, when the observable scale is recovered by $A=\exp \left[f_{2}(x)\right]$ and $\rho=\exp \left[g_{2}(x)\right]$, the new inflection point $x^{(o)}$ is shifted in relation to $x^{*}$ (Fig.3C-D). Accordingly, $\bar{\mu}_{N}$ and $\bar{\mu}_{S}$ produce $x^{*}$ as a fix parameter taking place in bare soil $(x<0)$. However, $\bar{\mu}_{A}$ and $\bar{\mu}_{\rho}$ result in $x^{(o)}>0$, meaning that the inflection is shifted for the patch domain. Therefore, there is a clear symmetry breaking related to the scale change, meaning that $A$ and $N$ represent different aspects of abundances, while $\rho$ and $S$ indicate different aspects of species density.
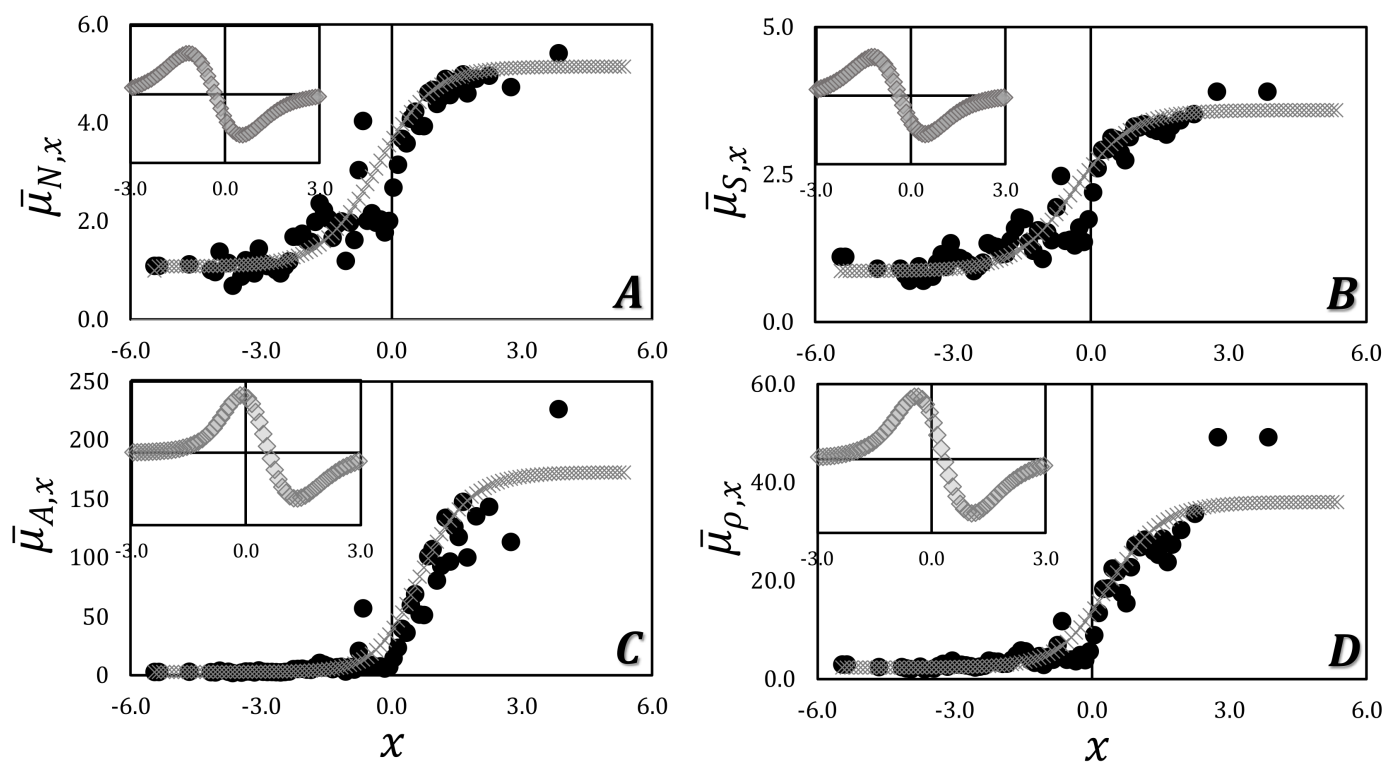

Figure 3. Comparing average abundances and species richness along a spatial representation that crosses the patch border $(x=0), x>0$ : patch size (radius); $x<0$ : distance from patch border. Filled rounded scatters are data, and small marks are logistic functions. On top, the consensus curve describing $\bar{\mu}_{N}$ (left) and $\bar{\mu}_{S}$ (right), which consider data at log scale. In the bottom, the $\bar{\mu}_{A}=\exp \left(\bar{\mu}_{N}\right)$ (left) and $\bar{\mu}_{R}=\exp \left(\bar{\mu}_{S}\right)$ (right), meaning that data are at observable scale. In the logarithm scale, the consensus curve show higher imprecision for $x<0$ than for $x>0$. In the observable scale, the imprecision vanishes for $x<0$. Insets in Figs. $A \rightarrow D$ depict the second-order derivative of average values and how the scale change shifts the thresholds.

Finally, it is possible to determine how changes in the carrying capacities (indicated by $N_{\max }$ and $\left.S_{\max }\right)$ taken in the log-scale shifts the respective inflection points $x^{(o)}$ when data are analyzed in the observed scale $\left(A\right.$ and $\rho$ ). Accordingly, the numerical integration of $\exp \left[f_{2}(x)\right]$ and $\exp \left[g_{2}(x)\right]$ for multiple values of $N_{\max }$ and $S_{\max }$ indicate that the inflection point $x^{(o)}$ is shifted to positive coordinates of $x$ (Fig.4A-D). The Fig.4 depicts that a linear increase of $N_{\max }$ and $S_{\max }[A=\exp (N)$ and $\rho=\exp (S)]$ produce a logarithmic shift in values of $x^{(o)}$. Therefore, these results indicate that, for the observable scale, the exponential increase of the maximum values of $N$ and $S$ produce a logarithmic shift of the main inflection point in direction to interpatches. Furthermore, the carrying capacity seems also affect the patterns inside patches. These results suggest that observable and logarithmic scale could be reflecting distinct ecological aspects related to soil arthropods (see Section4.2). 

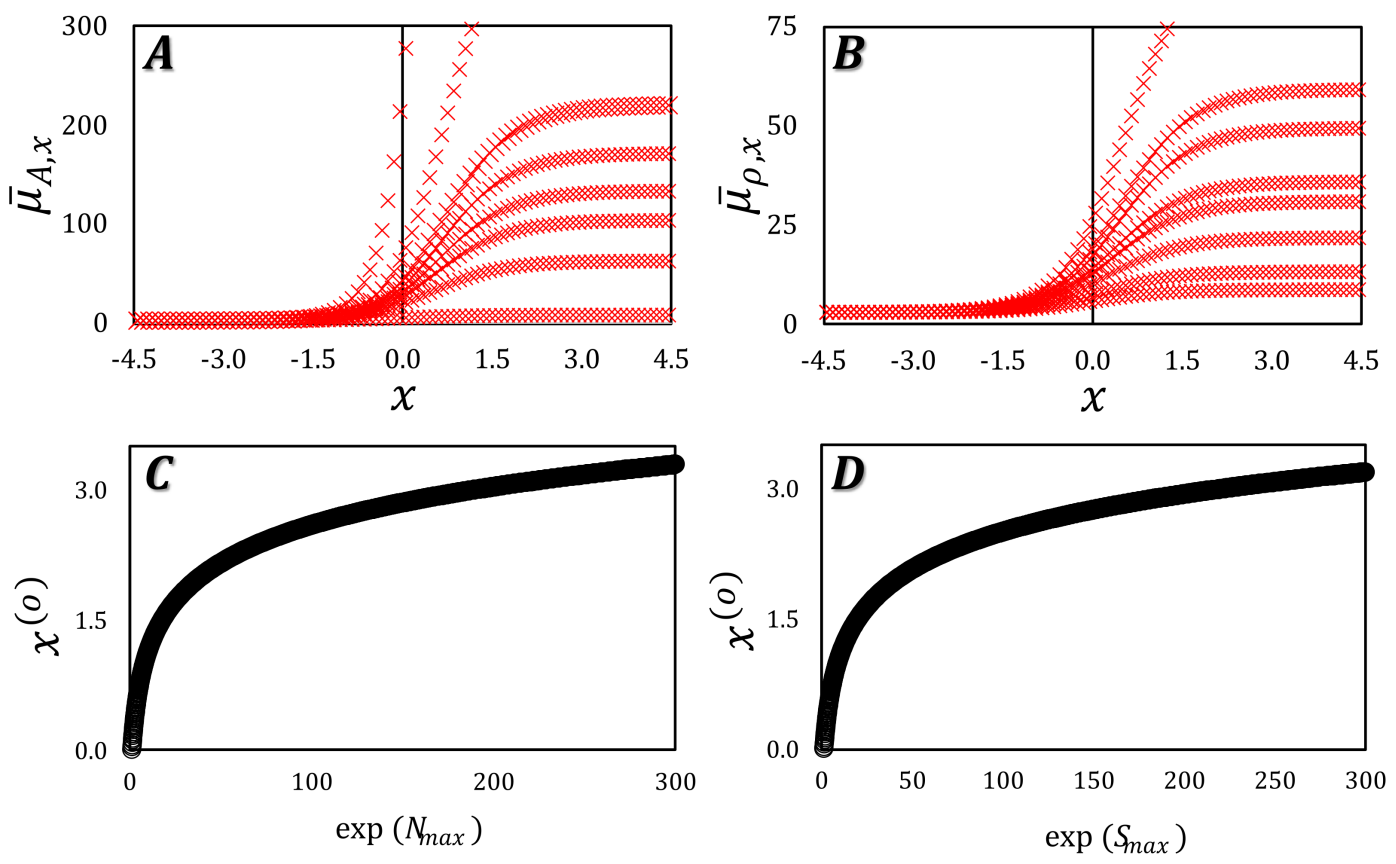

Figure 4. Effect of carrying capacity on the expected thresholds $x^{(o)}$ for observable average abundances $\left(\bar{\mu}_{A}\right)$ and average species density $\left(\bar{\mu}_{\rho}\right)$ found in soil throughout the spatial representation. Different from $x^{*}$, that is not affected by variations in the carrying capacity, $x^{(o)}$ values are shifted by $\exp \left(N_{\max }\right)$ and $\exp \left(S_{\max }\right)$ as logarithm. Therefore, one is clear that the the observable and the logarithm scale of arthropod communities represent distinct aspects of these communities.

\section{Discussion}

\subsection{Influence of the spatial arrangement of patches on fauna}

Our findings confirm that variations in abundances and species densities of soil arthropods can be understood as a continuous space, which crosses the patch borders. Furthermore, it is possible to detect a region of maximum uncertainty, validated by two distinct statistical measures, the averages and variances, which takes place in the bare soil. This interpatch coordinate reveals where soil arthropods community transitions from a poor and little structured community to a richer and structured one. The explanation relies on the fact that soil health is closely related to the arthropods activity[34-36,54], and these arthropods depend on resources and protection provided by plants[24,33]. Accordingly, one expects that abundances and species densities would increase as closer the interpatch is from the patch border, as consequence of the local amelioration produced by plants. Therefore, this evidence offers an objective indication of the range of long term effects provided by plant facilitation to the upper soil layers.

Data of soil arthropods analyzed in the logarithm scale revealed that plants provide long range facilitation. The result points out that important effects of the positive influence are observed until $0.35 \rightarrow 0.50 \mathrm{~m}$ far from the patch border in direction of bare soil, although the extreme case may overcome $1.00 \mathrm{~m}$. Interesting, the limit of facilitation almost matches the minimum patch radius $(\approx 0.50 \mathrm{~m})$ able to support a large and diverse community. These thresholds infer that soil samples taken in patches smaller than the minimum size show diversity patterns equivalent to interpatch regions located near to the patch border. This also reveals the importance of vegetation spatial patterns for the biological activity of soil, and how plant facilitation can be affected by patch size.

Patch sizes and plant facilitation are subjects often used to investigate the mechanisms able to maintain vegetation in drylands, as well as to predict processes able to trigger the desertification[18, $23,44,55,56]$. Although some modeling approaches consider the facilitation range as the underlying mechanism to describe the spatial patterns and dynamics of vegetation in drylands[18,57-61], the 
role the range of plant facilitation and minimum patch sizes in such dynamics remain little explored. Previous findings already pointed out the role of patch sizes for the maintenance of biodiversity and for the local amelioration, as well as for the functioning of drylands through plant-plant interactions[3, $14,16,18,20,62]$. In fact, large patches located close to each other tend to increase vegetation connectivity and affect the water infiltration[28,29,63]. A recent study also reveals that plant facilitation emerges from the coalescence between patches, meaning that one would be expected the existence of a minimum threshold of vegetation cover driving this process[45]. However, no one of these studies could show the range of facilitation or the minimum patch-sizes. In this sense, our findings introduce important updates for modeling approaches, or even for practical contexts. Indeed, they (a) corroborate predictions from previous studies about the role of measurable constraints for the ecology of drylands, and (b) also reveal the specific values for the facilitation range for the biological activity in the soil. Then, next future studies may use this information to obtain new insights about the ecological mechanisms that create vegetation spatial patterns and maintain the ecological functionality of drylands.

\subsection{Comparing patterns obtained in different scales}

The parameters $x^{*}$ and $x^{(o)}$ are obtained from same logistic functions, but they represent distinct behaviors. For instance, the logistic functions are always obtained as $N_{x}=f_{2}(x)$ or $S_{x}=g_{2}(x)$, and always consider faunal variables in their logarithm form. One means that the transposing to the observable scale assume a different form. Then, one is clear that Eq.4 and Eq.5 show distinct behaviors, which mathematically explain the difference between $x^{*}$ and $x^{(o)}$ (Fig2-3; Fig.3-4).

The distinct mathematical behavior also suggests that two ecological aspects can be inferred from the same variables and that each scale highlight a different one. The first one refers to the logarithm scale, and part of the interpretation is already explored throughout the document. The log-scale reduces differences between data showing different orders of magnitude, and permit to analyze behaviors that are not evident in other circumstances[44,64]. As abundances and species densities of soil arthropods from patches and interpatches differ in magnitude, the employment of $N$ and $S$ allowed us to reveal minor effects of plants in the bare soil regions, which we interpret as the range of facilitation. According with the definitions here adopted, changes in soil communities verified at log-scale fit the long range facilitation.

However, the long-range facilitation, indicated by $N$ and $S$, seems not to match another concept, which refers to the quantitative functionality in soil, which introduces the second aspect. As already mentioned, meso and microarthropods are often employed to indicate soil health[36]. Usually, the methods of bioindication employing soil arthropods to infer about soil properties address basic information of abundances, number of taxa, presence of particular taxa, ad hoc information, or even combination of metrics, to formulate indexes and quantitatively relate them with the functioning of soil processes[32,34,50,65,66]. Hence, the indication relies on the active role of these groups for the soil processes, which relies on the fact that each living organism presents an individual small contribution for the whole process[33,67-69]. Then, we may link this information with our results. It is expected that threshold $x^{(o)}$, which is obtained for the observable scale quantities $A$ and $\rho$, could better-reflect soil functionality than the logarithm transformed values $N$ and $S$ can do. Furthermore, the same interpretation indicates that soil processes are efficient only into large patches, meaning that the efficiency of ecological processes like nutrient cycling are defined by patches, mainly by the large ones. Accordingly, with our definitions, these main effects fit the constrained facilitation.

This hypothesis also makes great sense with our data, because the increase in the carrying capacity shifts the inflection point $x^{(o)}$ to the center of the patch $(x \gg 0)$. In fact, the increasing of carrying capacity means that large patches would present even higher functionality in soil, because they would also show more individuals and species, exploring more niches. If true, this would also introduce spatial heterogeneity inside the patches, in a process that finds similarity with the border effect in tropical forests[70]. Despite this possibility seems plausible in theory, it seems that does not hold for the studied region. From the best of our efforts, we could not find patches with so large carrying 
capacity, despite the number of individuals and species greatly vary among samples obtained in large patches. Then, the hypothesis raised by the numerical tests indicates that so high carrying capacity (and consequent soil functionality) is only possible for environments with higher primary productivity.

Then, we call attention for the fact that the different behaviors presented by $x^{*}$ and $x^{(o)}$ are not mere mathematical artifacts, because the evidence suggests that they actually reveal information from different ecological effects, each one better observed on a specific scale. Note that the long range facilitation and constrained facilitation are not contrasting, but are indeed two complementary aspects of the facilitation produced by plants. On one hand, the long range facilitation shows small effects for large relative area. On the other, the constrained facilitation shows intense effects, which are limited to the patch domain. The partitioning of facilitation provided by plants makes great sense for the understanding of the biological communities as whole. In harsh communities, the plants are not only the main primary conditions, but also facilitate that further plants, invertebrates, vertebrates and microorganisms find appropriate conditions to grow. Obviously, the species or guilds show physiological particularities and tend to explore different niches, meaning that they are also impacted in different manners by the amelioration produced by plants[33,69,71,72], which finally defines the efficiency of different soil functions. Hence, our findings reinforce the necessity of analyzing facilitation by its components. This is an important information that can be used to plan the conservation and restoration actions in drylands.

\section{Conclusions}

We demonstrate that variations in abundance and species density of soil arthropods found in patches and interpatches of drylands can be described as a continuous pattern. This description also revealed where the community patterns change from simple communities to abundant and highly diverse communities, indicating to exist a clear region of switching. This region takes place in bare soil, between $0.35 \mathrm{~m}$ and $0.50 \mathrm{~m}$ from the patch border, and it is inferred as the facilitation provided by plants on the bare soil regions. Our findings also show that the activity of soil arthropods reveals two distinct types of facilitation, long-range facilitation, with small effects for soil amelioration but long extension; and the constrained facilitation, with intense amelioration of soil but short extension. Our findings update important aspects related to the ecology of drylands and provide insights for projects focused on practical conservation. They can also be used to improve the theoretical models aimed to explain the pattern formation and the dynamics of these ecosystems.

Author Contributions: Both authors constributed equally for this paper.

Funding: “This research was funded by FAPESP 13/06196-4 and CAPES 88887.363718/2019-00, Finance Code 001." https:/ /bv.fapesp.br/pt/pesquisador/668540/ and CNPq 309851/2018-1.

Acknowledgments: F.M. and A.S. Martinez thank to São Paulo Research Foundation (FAPESP, grant 2013/06196-4) and to Coordination of Superior Level Staff Improvement -Brazil (CAPES), Finance Code 001. Thank to the team of Instituto Nacional de Ciência e Tecnologia de Sistemas Complexos (INCT-SC), Brazil, and to the team of the Dep. of Physics, FFCLRP, University of São Paulo for the administrative support. Special thanks to Susana Bautista and to Department of Ecology, University of Alicante, Spain, for providing hosting and facilities during the early stages of the research.

Conflicts of Interest: 'The authors declare no conflict of interest."

\section{Abbreviations}

The following abbreviations are used in this manuscript: 
A: abundance; $N=\ln (A)$;

$\rho$ : species density; $S=\ln (\rho)$;

$R$ : patch radius $(\mathrm{m})$;

$\bar{D}$ : average distance between interpatch middle region and its four-nearest patches $(\mathrm{m})$;

$x$ : continuous 1-d representation of $R$ and $\bar{D}(\mathrm{~m})$;

$\Delta x$ : regular discrete intervals of $x$;

$\bar{\mu}_{N}$ and $\bar{\mu}_{S}=$ average values of $N$ and $S$ in a given interval $\Delta x$;

$\sigma_{N}^{2}$ and $\sigma_{S}^{2}=$ variance of $N$ and $S$ in a given interval $\Delta x$;

$Y(x)$ : generic representation of $N$ or $S$ in the logistic function; $\Phi(x)=\exp [Y(x)]$;

$f_{1 \rightarrow 3}(x)$ and $g_{1 \rightarrow 3}(x)$ : logistic functions fitted for data;

$f_{1 \rightarrow 3}^{\prime \prime}(x)$ and $g_{1 \rightarrow 3}^{\prime \prime}(x)$ : second-order derivative of $f_{1 \rightarrow 3}(x)$ and $g_{1 \rightarrow 3}(x)$;

$x^{*}=$ inflection point of $f_{1 \rightarrow 3}(x)$ or $g_{1 \rightarrow 3}(x)$;

$x_{a}^{*}$ and $x_{b}^{*}=$ regions of interest of $f_{1 \rightarrow 3}(x)$ and $g_{1 \rightarrow 3}(x)$;

$x^{(o)}=$ inflection point for $\exp \left[f_{1 \rightarrow 3}(x)\right]$ or $\exp \left[g_{1 \rightarrow 3}(x)\right]$;

\section{Appendix A}

Appendix A.1
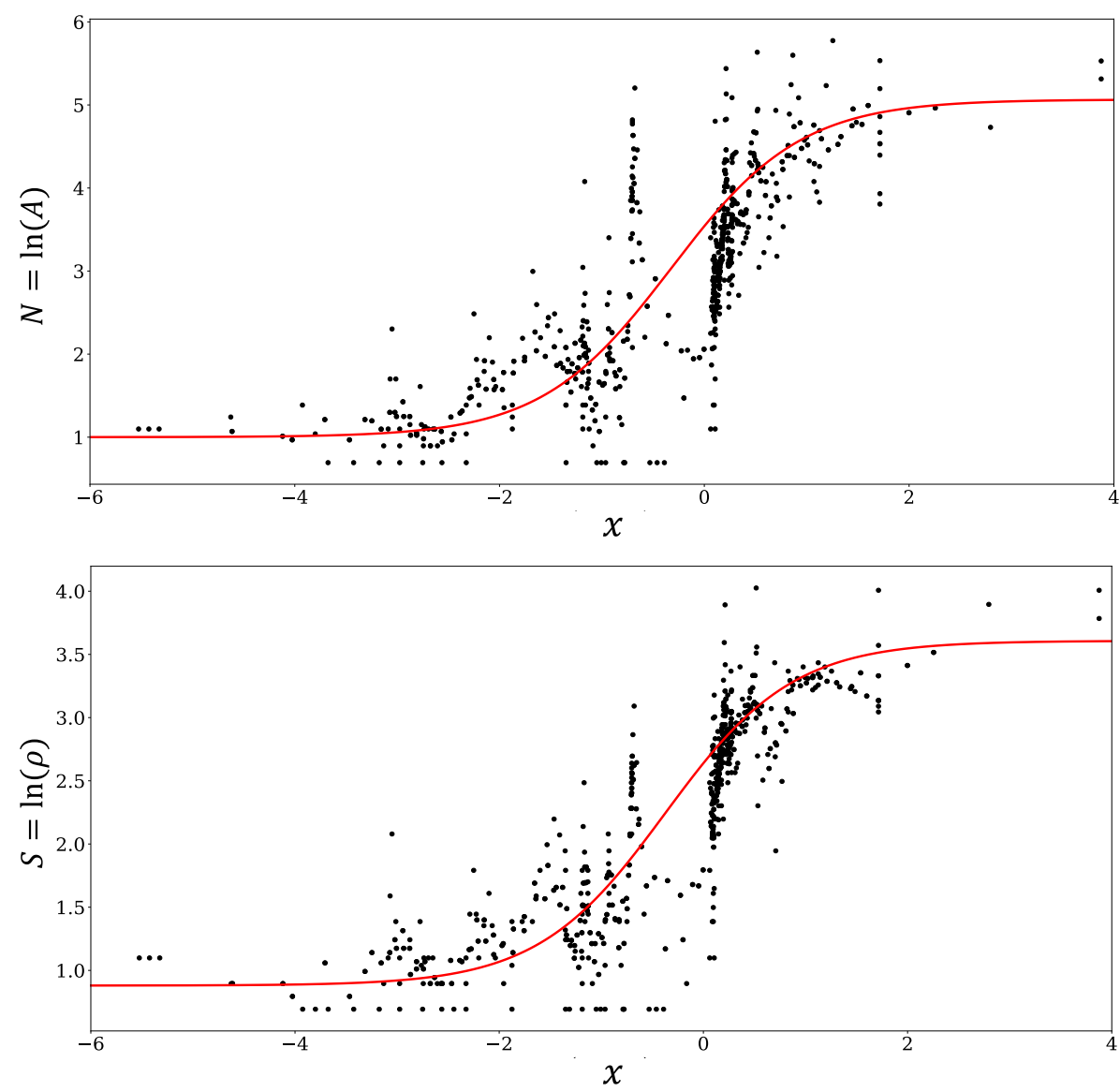

Figure A1. Abundances $(A)$ and species density $(\rho)$ plotted against $x$ as raw data, after the inclusion of pseudo-samples produced by moving averages. Continuous red lines are logistic functions and represent the average behavior of data.

\section{References}

1. Whitford, W. Ecology of Desert Systems; Academic Press: San Diego, USA, 2002. 
2. Delgado-Baquerizo, M.; Maestre, F.T.; Reich, P.B.; Jeffries, T.C.; Gaitan, J.J.; Encinar, D.; Berdugo, M.; Campbell, C.D.; Singh, B.K. Microbial diversity drives multifunctionality in terrestrial ecosystems. Nature Communications 2016, 7, 1-8. doi:10.1038/ncomms10541.

3. Maestre, F.T.; Eldridge, D.J.; Soliveres, S.; Kéfi, S.; Delgado-Baquerizo, M.; Bowker, M.A.; García-Palacios, P.; Gaitán, J.; Gallardo, A.; Lázaro, R.; Berdugo, M. Structure and Functioning of Dryland Ecosystems in a Changing World. Annual Review of Ecology, Evolution, and Systematics 2016, 47, 215-237.

4. Millennium Ecosystem Assessment (Program). Ecosystems and Human Well-being: Desertification Synthesis. World Resources Institute, 2005.

5. Millennium Ecosystem Assessment (Program). Ecosystems and Human Well-being: Biodiversity Synthesis. World Resources Institute, 2005.

6. Laliberté, E.; Zemunik, G.; Turner, B.L. Environmental filtering explains variation in plant diversity along resource gradients. Science 2014, 345, 1602-1605. doi:10.1126/science.1256330.

7. Delgado-Baquerizo, M.; Bardgett, R.D.; Vitousek, P.M.; Maestre, F.T.; Williams, M.A.; Eldridge, D.J.; Lambers, H.; Neuhauser, S.; Gallardo, A.; García-Velázquez, L.; Sala, O.E.; Abades, S.R.; Alfaro, F.D.; Berhe, A.A.; Bowker, M.A.; Currier, C.M.; Cutler, N.A.; Hart, S.C.; Hayes, P.E.; Hseu, Z.Y.; Kirchmair, M.; Peña-Ramírez, V.M.; Pérez, C.A.; Reed, S.C.; Santos, F.; Siebe, C.; Sullivan, B.W.; Weber-Grullon, L.; Fierer, N. Changes in belowground biodiversity during ecosystem development. Proceedings of the National Academy of Sciences 2019, 116, 6891-6896. doi:10.1073/pnas.1818400116.

8. Berdugo, M.; Maestre, F.T.; Kéfi, S.; Gross, N.; Le Bagousse-Pinguet, Y.; Soliveres, S. Aridity preferences alter the relative importance of abiotic and biotic drivers on plant species abundance in global drylands. Journal of Ecology 2019, 107, 190-202. doi:10.1111/1365-2745.13006.

9. Berdugo, M.; Soliveres, S.; Kéfi, S.; Maestre, F.T. The interplay between facilitation and habitat type drives spatial vegetation patterns in global drylands. Ecography 2019, 42, 755-767. doi:10.1111/ecog.03795.

10. Baruah, G.; Clements, C.F.; Ozgul, A. Eco-evolutionary processes underlying early warning signals of population declines. Journal of Animal Ecology 2019, 0, [https://besjournals.onlinelibrary.wiley.com/doi/pdf/10.1111/1365-2656.13097]. doi:10.1111/1365-2656.13097.

11. Maestre, F.T.; Callaway, R.M.; Valladares, F.; Lortie, C.J. Refining the stress-gradient hypothesis for competition and facilitation in plant communities. Journal of Ecology 2009, 97, 199-205. doi:10.1111/j.1365-2745.2008.01476.x.

12. McCluney, K.E.; Belnap, J.; Collins, S.L.; González, A.L.; Hagen, E.M.; Nathaniel Holland, J.; Kotler, B.P.; Maestre, F.T.; Smith, S.D.; Wolf, B.O. Shifting species interactions in terrestrial dryland ecosystems under altered water availability and climate change. Biological Reviews 2012, 87, 563-582. doi:10.1111/j.1469-185X.2011.00209.x.

13. Bruno, J.F.; Stachowicz, J.J.; Bertness, M.D. Inclusion of facilitation into ecological theory. Trends in Ecology E Evolution 2003, 18, 119 - 125. doi:https:/ / doi.org/10.1016/S0169-5347(02)00045-9.

14. Cortina, J.; Maestre, F. Plant Effects on Soils in Drylands: Implications for Community Dynamics and Ecosystem Restoration. In Tree Species Effects on Soils: Implications for Global Change; Binkley, D.; Menyailo, O., Eds.; Springer Netherlands, 2006; pp. 85-118. doi:10.1007/1-4020-3447-4_6.

15. Brooker, R.W.; Maestre, F.T.; Callaway, R.M.; Lortie, C.L.; Cavieres, L.A.; Kunstler, G.; Liancourt, P.; Tielbörger, K.; Travis, J.M.J.; Anthelme, F.; Armas, C.; Coll, L.; Corcket, E.; Delzon, S.; Forey, E.; Kikvidze, Z.; Olofsson, J.; Pugnaire, F.; Quiroz, C.L.; Saccone, P.; Schiffers, K.; Seifan, M.; Touzard, B.; Michalet, R. Facilitation in plant communities: the past, the present, and the future. Journal of Ecology 2008, 96, 18-34. doi:10.1111/j.1365-2745.2007.01295.x.

16. Pugnaire, F.; Armas, C.; Maestre, F. Positive plant interactions in the Iberian Southeast: Mechanisms, environmental gradients, and ecosystem function. Journal of Arid Environments 2011, 75, 1310 - 1320. Deserts of the World Part IV: Iberian Southeast, doi:https://doi.org/10.1016/j.jaridenv.2011.01.016.

17. Michalet, R.; Pugnaire, F.I. Facilitation in communities: underlying mechanisms, community and ecosystem implications. Functional Ecology 2016, 30, 3-9. doi:10.1111/1365-2435.12602.

18. Kéfi, S.; Rietkerk, M.; Alados, C.L.; Pueyo, Y.; Papanastasis, V.P.; ElAich, A.; De Ruiter, P.C. Spatial vegetation patterns and imminent desertification in Mediterranean arid ecosystems. Nature 2007, $449,213-217$. 
19. Gandhi, P.; Iams, S.; Bonetti, S.; Silber, M. Vegetation Pattern Formation in Drylands. In Dryland Ecohydrology; D'Odorico, P.; Porporato, A.; Wilkinson Runyan, C., Eds.; Springer International Publishing, 2019; pp. 469-509.

20. Escudero, A.; Giménez-Benavides, L.; Iriondo, J.M.; Rubio, A. Patch Dynamics and Islands of Fertility in a High Mountain Mediterranean Community. Arctic, Antarctic, and Alpine Research 2004, 36, 518-527. doi:10.1657/1523-0430(2004)036[0518:PDAIOF]2.0.CO;2.

21. Fuentes, E.; Otaiza, R.; Alliende, M.; Hoffmann, A.; Poiani, A. Shrub clumps of the Chilean matorral vegetation: structure and possible maintenance mechanisms. Oecologia 1984, 62, 405-411. doi:10.1007/BF00384275.

22. Stachowicz, J. Mutualism, Facilitation, and the Structure of Ecological Communities. BioScience 2001, 51, 235-245. doi:10.1641/0006-3568(2001)051[0235:MFATSO]2.0.CO;2.

23. Xu, C.; Holmgren, M.; Van Nes, E.H.; Maestre, F.T.; Soliveres, S.; Berdugo, M.; Kéfi, S.; Marquet, P.A.; Abades, S.; Scheffer, M. Can we infer plant facilitation from remote sensing? a test across global drylands. Ecological Applications 2015, 25, 1456-1462. doi:10.1890/14-2358.1.

24. Synodinos, A.D.; Tietjen, B.; Jeltsch, F. Facilitation in drylands: Modeling a neglected driver of savanna dynamics. Ecological Modelling 2015, 304, 11 - 21. doi:https:/ /doi.org/10.1016/j.ecolmodel.2015.02.015.

25. Uselman, S.M.; Davison, J.; Baughman, O.W.; Sullivan, B.W.; Miller, W.W.; Leger, E.A. Restoring dryland old fields with native shrubs and grasses: Does facilitation and seed source matter? PLOS ONE 2018, 13, 1-27. doi:10.1371/journal.pone.0205760.

26. Trautz, A.C.; Illangasekare, T.H.; Rodriguez-Iturbe, I. Role of co-occurring competition and facilitation in plant spacing hydrodynamics in water-limited environments. Proceedings of the National Academy of Sciences 2017, 114, 9379-9384. doi:10.1073/pnas.1706046114.

27. Steven, B.; Antoninka, A.J.; Babin, D.; Bastida, F.; Bowker, M.A.; Büdel, B.; Cowan, D.A.; de Scally, S.Z.; Eldridge, D.J.; Garcia, C.; Green, T.G.A.; Hemkemeyer, M.; Hernandez, T.; King, G.M.; Moreno, J.L.; Ndinga Muniania, C.; Porras-Alfaro, A.; Pronk, G.J.; Reed, S.; Smalla, K.; Tebbe, C.C. The Biology of Arid Soils, first edition ed.; Walter de Gruyter GmbH: Berlin, Germany, 2017.

28. Mayor, Á.G.; Kéfi, S.; Bautista, S.; Rodríguez, F.; Cartení, F.; Rietkerk, M. Feedbacks between vegetation pattern and resource loss dramatically decrease ecosystem resilience and restoration potential in a simple dryland model. Landscape Ecology 2013, 28, 931-942. doi:10.1007/s10980-013-9870-4.

29. Mayor, A.G.; Bautista, S.; Rodriguez, F.; Kéfi, S. Connectivity-Mediated Ecohydrological Feedbacks and Regime Shifts in Drylands. Ecosystems 2019, 22, 1497-1511. doi:10.1007/s10021-019-00366-w.

30. McGeoch, M.A. The selection, testing and application of terrestrial insects as bioindicators. Biological Reviews 1998, 73, 181-201. doi:10.1017/S000632319700515X.

31. Tiede, Y.; Schlautmann, J.; Donoso, D.A.; Wallis, C.I.; Bendix, J.; Brandl, R.; Farwig, N. Ants as indicators of environmental change and ecosystem processes. Ecological Indicators 2017, 83, 527 - 537. doi:https:/ / doi.org/10.1016/j.ecolind.2017.01.029.

32. Meloni, F. The influence of forest development on edaphic and epigeic Arthropod communities and ant fauna: bases for bioindicantion of successional process in ecological restoration. PhD thesis, University of São Paulo, Ribeirão Preto, SP, Brazil, 2012.

33. Coleman, D.C.; Callaham, M.A.; Crossley, D. Fundamentals of Soil Ecology (Third Edition), third edition ed.; Academic Press, 2018.

34. Parisi, V.; Menta, C.; Gardi, C.; Carlo, J.; Mozzanica, E. Microarthropod communities as a tool to assess soil quality and biodiversity: A new approach in Italy. Agriculture Ecosystems E Environment 2005, pp. 323-333. doi:10.1016/j.agee.2004.02.002.

35. Parisi, V.; Menta, C.; Gardi, C.; Carlo, J.; Mozzanica, E. Microarthropod communities as a tool to assess soil quality and biodiversity: A new approach in Italy. Agriculture Ecosystems E Environment 2005, pp. 323-333. doi:10.1016/j.agee.2004.02.002.

36. Menta, C.; Conti, F.D.; Pinto, S.; Bodini, A. Soil Biological Quality index (QBS-ar): 15 years of application at global scale. Ecological Indicators 2018, 85, 773 - 780. doi:https://doi.org/10.1016/j.ecolind.2017.11.030.

37. Doblas-Miranda, E.; Sánchez-Piñero, F.; González-Megías, A. Different structuring factors but connected dynamics shape litter and belowground soil macrofaunal food webs. Soil Biology and Biochemistry 2009, 41, 2543 - 2550. doi:https://doi.org/10.1016/j.soilbio.2009.09.014. 
38. Liu, J.L.; Li, F.R.; Liu, C.A.; Liu, Q.J. Influences of shrub vegetation on distribution and diversity of a ground beetle community in a Gobi desert ecosystem. Biodiversity and Conservation 2012, 21, 2601. doi:10.1007/s10531-012-0320-4.

39. Liu, R.; Zhu, F.; Steinberger, Y. Changes in ground-dwelling arthropod diversity related to the proximity of shrub cover in a desertified system. Journal of Arid Environments 2016, 124, 172 - 179. doi:https://doi.org/10.1016/j.jaridenv.2015.08.014.

40. Civieta, B.M. Impact of changes in vegetation cover and pattern on the edaphic fauna in drylands. Master's thesis, University of Alicante, San Vicente del Raspeig, Spain, 2015.

41. Meloni, F.; F. Civieta, B.; A. Zaragoza, J.; Lourdes Moraza, M.; Bautista, S. Vegetation Pattern Modulates Ground Arthropod Diversity in Semi-Arid Mediterranean Steppes. Insects 2020, 11. doi:10.3390/insects11010059.

42. United Nations, F.A.O. World reference base for soil resources 2014: International soil classification system for naming soils and creating legends for soil maps; World soil resources reports, Food and Agriculture Organization: Rome, Italy, 2014.

43. Oñate, J.J.; Peco, B. Policy impact on desertification: stakeholders' perceptions in southeast Spain. Land Use Policy 2005, 22, 103 - 114. doi:https:/ / doi.org/10.1016/j.landusepol.2004.01.002.

44. Meloni, F.; Granzotti, C.R.F.; Bautista, S.; Martinez, A.S. Scale dependence and patch size distribution: clarifying patch patterns in Mediterranean drylands. Ecosphere 2017, 8.

45. Meloni, F.; Nakamura, G.M.; Granzotti, C.R.; Martinez, A.S. Vegetation cover reveals the phase diagram of patch patterns in drylands. Physica A: Statistical Mechanics and its Applications 2019, 534, 122048. doi:https://doi.org/10.1016/j.physa.2019.122048.

46. Verwijmeren, M.; Rietkerk, M.; Bautista, S.; Mayor, A.G.; Wassen, M.J.; Smit, C. Drought and grazing combined: Contrasting shifts in plant interactions at species pair and community level. Journal of Arid Environments 2014, 111, 53 - 60. doi:https://doi.org/10.1016/j.jaridenv.2014.08.001.

47. Verwijmeren, M.; Smit, C.; Bautista, S.; Wassen, M.J.; Rietkerk, M. Combined Grazing and Drought Stress Alter the Outcome of Nurse: Beneficiary Interactions in a Semi-arid Ecosystem. Ecosystems 2019, 22, 1295-1307. doi:10.1007/s10021-019-00336-2.

48. Meloni, F.; Varanda, E.M. Litter and soil arthropod colonization in reforested semi-deciduous seasonal Atlantic forests. Restoration Ecology 2015, 23, 690-697. doi:10.1111/rec.12236.

49. Meron, E.; Bennett, J.J.R.; Fernandez-Oto, C.; Tzuk, O.; Zelnik, Y.R.; Grafi, G. Continuum Modeling of Discrete Plant Communities: Why Does It Work and Why Is It Advantageous? Mathematics 2019, 7. doi:10.3390/math7100987.

50. Moreira, F.M.; Huising, E.J.; Binell, D.E. A Handbook of Tropical Soil Biology: Sampling and Characterization of Below-ground Biodiversity, first edition ed.; EarthScan: London, UK, 2008; p. 256.

51. Stanley, H.E. Phase transitions and critical phenomena. Clarendon, Oxford 1971, p. 9.

52. Majumder, S.; Tamma, K.; Ramaswamy, S.; Guttal, V. Inferring critical thresholds of ecosystem transitions from spatial data. Ecology 2019, 100, e02722. doi:10.1002/ecy.2722.

53. Cramer, J. The early origins of the logit model. Studies in History and Philosophy of Science Part C: Studies in History and Philosophy of Biological and Biomedical Sciences 2004, 35, 613 - 626. doi:https://doi.org/10.1016/j.shpsc.2004.09.003.

54. Galli, L.; Capurro, M.; Menta, C.; Rellini, I. Is the QBS-ar index a good tool to detect the soil quality in Mediterranean areas? A cork tree Quercus suber L. (Fagaceae) wood as a case of study. Italian Journal of Zoology 2014, 81, 126-135. doi:10.1080/11250003.2013.875601.

55. Kéfi, S.; Guttal, V.; Brock, W.A.; Carpenter, S.R.; Ellison, A.M.; Livina, V.N.; Seekell, D.A.; Scheffer, M.; van Nes, E.H.; Dakos, V. Early Warning Signals of Ecological Transitions: Methods for Spatial Patterns. PLOS ONE 2014, 9, 1-13. doi:10.1371/journal.pone.0092097.

56. Berdugo, M.; Kéfi, S.; Soliveres, S.; Maestre, F.T. Plant spatial patterns identify alternative ecosystem multifunctionality states in global drylands. Nature Ecology E Evolution 2017, 1, 0003.

57. Kéfi, S.; Rietkerk, M.; Roy, M.; Franc, A.; De Ruiter, P.C.; Pascual, M. Robust scaling in ecosystems and the meltdown of patch size distributions before extinction. Ecology letters 2011, 14, 29-35.

58. Corrado, R.; Cherubini, A.M.; Pennetta, C. Early warning signals of desertification transitions in semiarid ecosystems. Physical Review E 2014, 90, 062705. 
59. Meron, E. Pattern-formation approach to modelling spatially extended ecosystems. Ecological Modelling 2012, 234, 70-82.

60. Gilad, E.; Shachak, M.; Meron, E. Dynamics and spatial organization of plant communities in water-limited systems. Theoretical population biology 2007, 72, 214-230.

61. von Hardenberg, J.; Kletter, A.Y.; Yizhaq, H.; Nathan, J.; Meron, E. Periodic versus scale-free patterns in dryland vegetation. Proceedings of the Royal Society of London B: Biological Sciences 2010, p. rspb20092208.

62. Maestre, F.T.; Escudero, A. Is the patch size distribution of vegetation a suitable indicator of desertification processes? Ecology 2009, 90, 1729-1735.

63. Tongway, D.; Hindley, N. Landscape Function Analysis: A System for Monitoring Rangeland Function. African Journal of Range and Forage Science 2004, 21. doi:10.2989/10220110409485841.

64. Cirillo, P. Are your data really Pareto distributed? Physica A: Statistical Mechanics and its Applications 2013, 392, 5947 - 5962. doi:https://doi.org/10.1016/j.physa.2013.07.061.

65. Yan, S.; Singh, A.; Fu, S.; Liao, C.; Wang, S.; Li, Y.; Cui, Y.; Hu, L. A soil fauna index for assessing soil quality. Soil Biology and Biochemistry 2012, 47, 158 - 165. doi:https://doi.org/10.1016/j.soilbio.2011.11.014.

66. Araújo, J.d.L.; Pastori, P.L.; Gomes, V.F.F.; Mendes Filho, P.F.; Nunes, L.A.P.L. Changes in the abundance and diversity of soil arthropods in the cultivation of fruit crops. Revista Ciência Agronômica 2018, 49, 537 546.

67. Seastedt, T.R. The Role of Microarthropods in Decomposition and Mineralization Processes. Annual Review of Entomology 1984, 29, 25-46. doi:10.1146/annurev.en.29.010184.000325.

68. Coleman, D.; Coleman, R.; Hendrix, P. Invertebrates as Webmasters in Ecosystems; CABI Publishing Series, CABI Pub., 2000.

69. Fitter, A.H.; Gilligan, C.A.; Hollingworth, K.; Kleczkowski, A.; Twyman, R.M.; Pitchford, J.W.; The members of the NERC Soil Biodiversity Programme. Biodiversity and ecosystem function in soil. Functional Ecology 2005, 19, 369-377. doi:10.1111/j.0269-8463.2005.00969.x.

70. Corlett, Richard, T.; Primack, R.B. Tropical Rain Forests an Ecological and Biogeographical Comparison, second edition ed.; John Wiley \& Sons, Ltd: Chichester, UK, 2011.

71. Coleman, D.C.; Whitman, W.B. Linking species richness, biodiversity and ecosystem function in soil systems. Pedobiologia 2005, 49, 479 - 497. doi:https://doi.org/10.1016/j.pedobi.2005.05.006.

72. Menta, C.; Remelli, S. Soil Health and Arthropods: From Complex System to Worthwhile Investigation. Insects 2020, 11. doi:10.3390/insects11010054.

Sample Availability: Data are available from the authors. 